\title{
Effect of cigarette smoking on evolution of ventilatory lung function in young adults: an eight year longitudinal study
}

\author{
Maritta S Jaakkola, Pierre Ernst, Jouni J K Jaakkola, Lucy W N'gan'ga, \\ Margaret R Becklake
}

\begin{abstract}
Background There are few data on the quantitative effects of cigarette smoking on lung function in young adults. These effects are important in the understanding of the early stages of chronic airflow obstruction.

Methods A longitudinal study over eight years was carried out to estimate quantitatively the effect of cigarette smoking on ventilatory lung function in young adults and to examine the possibility that the effect is modified by other factors. The study population were 15 to 40 years of age at initial examination, when they underwent spirometry and completed an interviewer administered questionnaire on respiratory health. Eight years later 391 of the subjects were re-examined (38\% response rate). The quantitative effect of cigarette smoking during the study period on the average change of forced expiratory volume in one second $\left(F E V_{1}\right)$ over time $\left(\delta F E V_{1}\right)$ was estimated in two linear regression models that included potential confounders and other determinants of outcome. Results The first model showed a significant dose-response relation between the average rate of smoking during the study period and $\delta \mathrm{FEV}_{1}$, giving an estimate of annual change in $\mathrm{FEV}_{1}$ of $-0.42 \mathrm{ml}$ for each cigarette smoked per day $(-8 \cdot 4 \mathrm{ml}$ for each pack $)(p=0.04)$. In the second model, which took smoking before the study period as a potential confounder, the effect of smoking during the study period was slightly smaller $(-0.33 \mathrm{ml} /$ year for each cigarette smoked per day). This indicated that smoking before the study period had a marginal latent effect on $\delta F E V_{1}$ during the study. However, neither the effect of smoking before the study nor that of smoking during the study was significant, presumably because of collinearity. Interactions between cigarette smoking and gender, wheezing, atopy, and exposure to environmental tobacco smoke during the growth period were not significant with respect to their effect on the relation between cigarette smoking and $\delta F E V$, Conclusion Cigarette smoking has a
\end{abstract}

dose related adverse effect on the evolution of ventilatory lung function in young adulthood.

\section{Introduction}

Understanding the early evolution of ventilatory impairment is important for the prevention of chronic obstructive pulmonary disease as this disease develops gradually over time and symptoms severe enough to raise concern appear at a late stage of the disease. Cigarette smoking has been identified to be the most important determinant of ventilatory impairment. ${ }^{1-25}$ In longitudinal studies smoking has been shown to impair the growth of forced expiratory volume in one second $\left(\mathrm{FEV}_{1}\right)$ in children $^{23}$ and cause an accelerated decline in $\mathrm{FEV}_{1}$ in adults. ${ }^{10-22}$ Only Fletcher et $a l^{25}$ and Peat et $a l^{22}$ have reported quantitative estimates of the association between the numbers of cigarettes smoked and the rate of decline of $\mathrm{FEV}_{1}$ in a regression model adjusting for age and, in the study of Fletcher et al, for mean $\mathrm{FEV}_{1} /$ height $^{3}$. Their study was carried out in a middle aged male population in London and the study of Peat et al in a population aged 20 years or older in Western Australia. Little is known about the magnitude of the effect of smoking in young adults.

In their eight year prospective study of 792 men Fletcher et al found that smoking seemed to affect only a subgroup of smokers, suggesting a susceptibility that could be affected by other environmental hazards. The determinants of susceptibility to the effects of smoking have been difficult to identify. Several other probable determinants of ventilatory function have been recognised, including genetic factors, atopy, non-specific airways hyperresponsiveness, childhood respiratory illness, the presence of respiratory symptoms, socioeconomic status, alcohol consumption, exposure to environmental tobacco smoke, outdoor air pollution, and certain occupational exposures. ${ }^{26} 27$ Their role as potential modifiers of the effects of cigarette smoking on ventilatory function, however, has yet to be studied. In our cross sectional study of the effects of smoking on lung function in young adults we found that the adverse effects of smoking were limited to a subgroup of subjects with wheezing, suggesting that wheezing is an important indicator of individual susceptibility. ${ }^{24}$ 
The objectives of the present study were to estimate quantitatively the effect of cigarette smoking during the study period on change in ventilatory function in young adults and to examine whether this effect is modified by other factors.

\section{Methods}

STUDY POPULATION

The baseline population consisted of 1044 young, white adults, who were 15 to 40 years of age at initial examination in 1980-1. The population was recruited from a high school, a junior college, and two banking institutions in Montreal. To be included the subject had to perform at least one acceptable spirometric test. More detailed description of the baseline population is given in a previous report. ${ }^{28}$ Follow up surveys were carried out in 1981-2 and $1982-3$. A total of 603 subjects $(58 \%$ of the baseline population) participated in the first follow up survey and 453 subjects $(43 \%)$ in the second survey.

In 1988-9 all subjects from the baseline study were contacted and asked to participate in a follow up study. To maximise follow up testing took place in Toronto as well as Montreal. In all, 395 subjects (38\% of the baseline population) had follow up spirometry measurements taken and answered the American Thoracic Society's respiratory questionnaire (ATS-DLD-78-A). ${ }^{29}$ of the 395 subjects retested, four were excluded-one because she was pregnant at the time of reexamination, two in whom no acceptable follow up spirometry tracings were obtained, and one subject whose $F E V_{1}$ at baseline was incorrect because of technical problems. Thus the study population consisted of 391 subjects -177 men $(45 \%)$ and 214 women (55\%). The mean (SD) follow up time was $7 \cdot 7(0 \cdot 49)$ years.

\section{SPIROMETRY}

The lung function measurements carried out during the initial survey have been described in detail. ${ }^{28}$ During the baseline study and the first two follow up surveys each subject performed three maximal expiratory flow manoeuvres, which were recorded with a heated Fleisch No 4 pneumotachograph. In the follow up study in 1988-9 the subjects performed forced vital capacity manoeuvres according to the standardised methods recommended by the American Thoracic Society. ${ }^{30}$ The aim was to get a minimum of three acceptable tracings. Spirometry was carried out using a 10 litre water sealed bell spirometer attached to a computer (Collins DSII/plus system), which provided results adjusted to BTPS according to ambient temperature and pressure measurements recorded twice a day. In each survey the equipment to record spirometry was calibrated daily by an independent measure of volume. The largest $\mathrm{FEV}_{1}$ value from the acceptable tracings in each survey was used in the analysis. The spirometry results of the first two follow up surveys were included in the analyses for those who participated in the $1981-2$ survey (266 subjects, $68 \%$ ) and/or in the 1982-3 survey (242 subjects, $62 \%$ ).

\section{QUESTIONNAIRES}

During the baseline study all subjects responded to an interviewer administered standardised questionnaire (ATS-DLD-78-A) with questions about exposure to environmental tobacco smoke during their period of growth added to the standard questionnaire. ${ }^{29}$ Those who performed lung function testing in 1988-9 answered the questionnaire again, on this occasion by using an interactive program on a personal computer.

\section{STATISTICAL METHODS \\ Outcome}

The outcome of interest was the rate of change of ventilatory lung function over time. The mean rate of change of $\mathrm{FEV}_{1}\left(\delta \mathrm{FEV}_{1}\right)$ during the study period was chosen as the outcome of the analysis. The slope of the change of $\mathrm{FEV}_{1}$ was calculated for each subject from the two to four available measurements at different times during the study by the least squares method. The outcome was used unadjusted in the analysis to leave it in its most understandable and natural form. This is in line with the suggestion of Vollmer et al. .1 $^{31}$

\section{Exposure}

The exposure to tobacco smoke of the study population was categorised according to the answers to the questionnaires at baseline and in 1988-9 as follows: (i) index category, which included continuous cigarette smoking (cigarette smoker in 1980-1 and in 1988-9) and cigarette smoking started during the study period (never smoker in 1980-1 and cigarette smoker in 1988-9); (ii) reference category, which included no exposure to tobacco smoke (never smoker in 1980-1 and in 1988-9); and (iii) other smoking category, which included all the other forms of exposure to tobacco smoke (cigarette smoker in 1980-1 who gave up smoking during the study period, former cigarette smoker in 1980-1 and in 1988-9, former cigarette smoker in 1980-1 who started smoking again during the study period, never smoker in 1988-9 and former cigarette smoker in 1988-9, current or former smoker of pipe or cigar, or both).

The main determinant of interest was cigarette smoking during the study period (index category). Cigarette smoking was measured quantitatively as the average rate of smoking during the study period (estimated as the average number of cigarettes smoked daily in 1988-9). Cigarette smoking before the study period was considered separately as a potential confounder of the effect of cigarette smoking during the study period on $\delta F_{E V}$. As the duration of earlier smoking varied considerably a cumulative exposure in cigarette years rather than average daily rate was used. Cumulative exposure was calculated by multiplying the duration of smoking before the study period by the average number of cigarettes smoked daily reported in the first questionnaire in 1980-1.

\section{Covariates}

All the potential determinants of $\delta \mathrm{FEV}_{1}$ were considered as potential confounders of the outcome-exposure relation. The following 
variates were examined: age, gender, height, Quetelet index $\left(100\right.$ (weight/height $\left.\left.^{2}\right)\right)$, baseline $\mathrm{FEV}_{1}$, wheezing, atopy, asthma diagnosed by a doctor, early childhood respiratory illness, exposure to environmental tobacco smoke during the growth period, and occupational exposure to dust or chemical fumes, or both, for a year or more.

Age is a major determinant of $\delta \mathrm{FEV}_{1}$ over the studied age range (15-40 years at baseline). In the natural evolution of ventilatory function the earlier age period studied belongs to the late growth phase, and the later age period studied is expected to show a gradual decline of lung function due to the normal aging process. ${ }^{32-34}$ Thus $\delta \mathrm{FEV}_{1}$ decreases from a positive value (during growth) through zero (plateau) to a negative value (decline in function) with aging. A linear relation between $\delta \mathrm{FEV}_{1}$ and age was assumed to be a good simple estimate. Baseline $\mathrm{FEV}_{1}$ was expected to affect $\delta \mathrm{FEV}_{1}$ because an absolute change rather than a proportional change was used as the outcome. Height and Quetelet index are physiological determinants of $\mathrm{FEV}_{1}$ and thus potential determinants of $\delta \mathrm{FEV}_{1}$.

Information on wheezing, atopy, asthma diagnosed by a doctor, early childhood respiratory illness, and occupational exposure to dust or chemical fumes, or both, was based on the standardised questions of the American Thoracic Society's questionnaire at the baseline interview. Wheezing was defined as being present when the subject answered yes to any of the following questions: "Does your chest ever sound wheezy or whistling when you have a cold?"-“'Occasionally apart from colds?""On most days and nights?" Wheezing was defined as being absent when the subject answered no to all three questions. The exposure to environmental tobacco smoke was classified according to the answer (yes or no) to the question: "Did any member of your family living at home smoke cigarettes while you were growing up?"

\section{Data analysis}

Simple linear regression of $\delta \mathrm{FEV}_{1}$ on age was calculated in men and women who had never smoked (the reference group) and smokers (the index group) to see if the assumption of a linear relation between $\delta \mathrm{FEV}_{1}$ and age was justified. Mean $\delta \mathrm{FEV}_{1}$ was studied in categories of other determinants.
The quantitative effect of cigarette smoking on $\delta \mathrm{FEV}_{1}$ was assessed in a multiple linear regression model, adjustment being made for all potential confounders to obtain an unbiased estimate. ${ }^{35}$ The quantitation of cigarette smoking (cigarettes per day) during the study period was included as the main determinant of interest. Cigarette smoking before the study period could have affected $\delta \mathrm{FEV}_{1}$ during the study directly, or indirectly through a decrease in baseline $\mathrm{FEV}_{1}$, which is a determinant of $\delta \mathrm{FEV}_{1}$. Adjustment for baseline $\mathrm{FEV}_{1}$ would be expected to control for only indirect confounding. As smoking before and during the study period were likely to be correlated inclusion of earlier smoking was problematic and models with and without earlier smoking were fitted.

In the regression analysis the contrast of cigarette smoking during the study period (index category) with never smoking (reference category) was achieved by including an indicator ("dummy") variate of the other smoking category (coding $1=$ yes, $0=$ no). Outcome in the reference category was thus defined when all the variates of smoking were 0 . The variates of smoking and all the covariates were fitted in the main effects model.

Cigarette smoking for the index category was expressed quantitatively with two variates: (1) the mean rate of cigarette smoking during the study period, and (2) the cumulative number of cigarettes smoked before the study period. The main interest was in the prospective study of the effect of cigarette smoking on $\delta \mathrm{FEV}_{1}$ during the study period. Two models to explain $\delta \mathrm{FEV}_{1}$ were fitted with different variates of quantitative smoking: model 1 with variate 1 only and model 2 with variates 1 and 2 as independent variates.

The question of sensitivity to the effects of smoking was addressed by studying modification in the additive model. The following variates were considered as potential modifiers: gender, wheezing, atopy, and exposure to environmental tobacco smoke during the growth period. The numbers of subjects with asthma (nine) and childhood respiratory illness (six) were too small to study. With all the potential confounders in the model modification of the effect of exposure was studied by introducing exposure-covariate product terms one by one and retaining them in the model according to the significance of the regression coefficient $(\mathrm{p}<0 \cdot 05) .^{35}$

Table 1 Baseline characteristics (continuous variates) of study population, those lost to follow up, and baseline population. Figures are mean (SE) values

\begin{tabular}{|c|c|c|c|c|c|c|}
\hline \multirow[b]{3}{*}{$\begin{array}{l}\text { Age (years) } \\
\text { FEV }(1) \\
\text { Forced vital capacity }(1) \\
\text { Height }(\mathrm{cm})\end{array}$} & \multicolumn{2}{|c|}{ Study population $\star$} & \multicolumn{2}{|c|}{ Subjects lost to follow up } & \multicolumn{2}{|c|}{ Baseline population } \\
\hline & $\begin{array}{l}\text { Males } \\
(n=177)\end{array}$ & $\begin{array}{l}\text { Females } \\
(n=214)\end{array}$ & $\begin{array}{l}\text { Males } \\
(n=240)\end{array}$ & $\begin{array}{l}\text { Females } \\
(n=409)\end{array}$ & $\begin{array}{l}\text { Males } \\
(n=418)\end{array}$ & $\begin{array}{l}\text { Females } \\
(n=626)\end{array}$ \\
\hline & $\begin{array}{cl}27 \cdot 6 & (0.43) \\
4.49 & (0.045) \\
5 \cdot 24 & (0.051) \\
176.4 & (0.49)\end{array}$ & $\begin{aligned} 25.4 & (0.36) \\
3.20 & (0.029) \\
3.65 & (0.036) \\
162.0 & (0.42)\end{aligned}$ & $\begin{array}{cl}25 \cdot 2 & (0.39) \dagger \\
4.50 & (0.044) \\
5 \cdot 22 & (0.047) \\
176.6 & (0.42)\end{array}$ & $\begin{aligned} 23.5 \dagger & (0.27) \\
3.22 & (0.022) \\
3.67 & (0.028) \\
162.4 & (0.31)\end{aligned}$ & $\begin{array}{cl}26.3 & (0.29) \\
4.49 & (0.032) \\
5.23 & (0.035) \\
176.5 & (0.32)\end{array}$ & $\begin{aligned} 24 \cdot 2 & (0 \cdot 22) \\
3 \cdot 21 & (0 \cdot 018) \\
3 \cdot 66 & (0 \cdot 022) \\
162 \cdot 3 & (0 \cdot 25)\end{aligned}$ \\
\hline
\end{tabular}

^Four subjects re-examined were excluded from the study population.

${ }_{t} p<0.05$ For the difference between the study population and those lost to follow up ( $t$ test). 
Table 2 Baseline characteristics (categorical variates) of study population, those lost to follow up, and baseline population. Figures are numbers (percentages) of subjects

\begin{tabular}{|c|c|c|c|c|c|c|}
\hline & \multicolumn{2}{|c|}{ Study population* } & \multicolumn{2}{|c|}{ Subjects lost to follow up } & \multicolumn{2}{|c|}{ Baseline population } \\
\hline & $\begin{array}{l}\text { Males } \\
(n=177)\end{array}$ & $\begin{array}{l}\text { Females } \\
(n=214)\end{array}$ & $\begin{array}{l}\text { Males } \\
(n=240) \dagger\end{array}$ & $\begin{array}{l}\text { Females } \\
(n=409)\end{array}$ & $\begin{array}{l}\text { Males } \\
(n=418)\end{array}$ & $\begin{array}{l}\text { Females } \\
(n=626)\end{array}$ \\
\hline \multicolumn{7}{|l|}{ Smoking status: } \\
\hline Current smoker & $39(22 \cdot 0)$ & $101(47 \cdot 2)$ & $64(26 \cdot 7)$ & $184(45 \cdot 0)$ & $103(24 \cdot 6)$ & $286(45 \cdot 7)$ \\
\hline Former smoker & $39(22 \cdot 0)$ & $24(11 \cdot 2)$ & $29(12 \cdot 1) \dagger$ & $54(13 \cdot 2)$ & $68(16 \cdot 3)$ & $78(12.5)$ \\
\hline Never smoker & $88(49 \cdot 7)$ & $87(40 \cdot 7)$ & $122(50 \cdot 8)$ & $169(41 \cdot 3)$ & $211(50 \cdot 5)$ & $258(41 \cdot 2)$ \\
\hline Pipe/cigar smoker & $11(6 \cdot 2)$ & $2(0.9)$ & $25(10.4)$ & $2(0.5)$ & $36 \quad(8 \cdot 6)$ & $4(0.6)$ \\
\hline \multicolumn{7}{|l|}{ Symptoms: } \\
\hline Cough & $19(10 \cdot 7)$ & $33(15 \cdot 4)$ & $22 \quad(9 \cdot 2)$ & $75(18 \cdot 3)$ & $41 \quad(9 \cdot 8)$ & $109(17 \cdot 4)$ \\
\hline Phlegm & $20(11 \cdot 3)$ & $29(13 \cdot 6)$ & $18(7 \cdot 5)$ & $60(14 \cdot 7)$ & $38 \quad(9 \cdot 1)$ & $90(14 \cdot 4)$ \\
\hline Wheezing & $44(24.9)$ & $71(33 \cdot 2)$ & $73(30 \cdot 4)$ & $176(43.0) \dagger$ & $117(28.0)$ & $248(39.6)$ \\
\hline Breathlessness & $19(10 \cdot 7)$ & $50(23.4)$ & $17(7 \cdot 1)$ & $102(24.9)$ & $36 \quad(8.6)$ & $153(24 \cdot 4)$ \\
\hline \multicolumn{7}{|l|}{ Respiratory history: } \\
\hline Asthma & $5 \quad(2 \cdot 8)$ & $4 \quad(1.9)$ & $17 \quad(7 \cdot 1)$ & $34(8 \cdot 3) \dagger$ & $22 \quad(5 \cdot 3)$ & $38 \quad(6 \cdot 1)$ \\
\hline Atopy & $58(32 \cdot 8)$ & $80(37 \cdot 4)$ & $86(35 \cdot 8)$ & $178(43.5)$ & $145(34 \cdot 7)$ & $260(41.5)$ \\
\hline Childhood respiratory illness & $4(2 \cdot 3)$ & $2(0.9)$ & $5(2 \cdot 1)$ & $10(2 \cdot 4)$ & $9(2 \cdot 2)$ & $12(1.9)$ \\
\hline \multicolumn{7}{|l|}{ Occupational exposure } \\
\hline \multicolumn{7}{|l|}{ to dust } \\
\hline $\begin{array}{l}\text { Occupational exposure } \\
\text { to chemicals }\end{array}$ & $8 \quad(4 \cdot 5)$ & $3(1.4)$ & $8 \quad(3 \cdot 3)$ & $9 \quad(2 \cdot 2)$ & $16 \quad(3 \cdot 8)$ & $12(1.9)$ \\
\hline
\end{tabular}

\section{Results}

COMPARISON OF BASELINE CHARACTERISTICS

Tables 1 and 2 give the baseline characteristics of the study population, subjects lost to follow up, and the original baseline population. There were significantly more men in the study population (45\%) than among subjects lost to follow up $(37 \%)$. The study population was significantly older than subjects lost to follow up ( $p$ $<0.05$ ) for both men and women, but their baseline $\mathrm{FEV}_{1}$ and forced vital capacity did not differ. The study population differed from those not followed up with respect to only two other baseline characteristics: self reported asthma diagnosed by a doctor and wheezing were less common among those re-examined than among those not followed up, the differences being significant only in women. There were no significant differences in the proportion of current cigarette smokers between the two groups.

Table 3 Smoking categories and details of amount smoked in the index category in the study population. Figures are numbers (percentages) of subjects

\begin{tabular}{|c|c|c|c|}
\hline & Males & Females & Total \\
\hline \multicolumn{4}{|c|}{ Category of exposure } \\
\hline Index: & $25(14 \cdot 1)$ & $78(36 \cdot 5)$ & $103(26 \cdot 3)$ \\
\hline Continuous cigarette smoker & $22(12 \cdot 4)$ & $77(36 \cdot 0)$ & $99(25 \cdot 3)$ \\
\hline Started cigarette smoking during follow up & $3(1 \cdot 7)$ & $1(0.5)$ & $4(1 \cdot 0)$ \\
\hline Reference (never smoker) & $82(46 \cdot 3)$ & $82(38 \cdot 3)$ & $164(42 \cdot 0)$ \\
\hline Other smoking & $70(39 \cdot 6)$ & $54(25 \cdot 2)$ & $124(31 \cdot 8)$ \\
\hline \multicolumn{4}{|c|}{ Index category } \\
\hline \multicolumn{4}{|l|}{$\begin{array}{l}\text { Average daily rate of } \\
\text { cigarette smoking during the study }{ }^{\star} \text { : }\end{array}$} \\
\hline $1-9$ & $6(24 \cdot 0)$ & $8(10 \cdot 2)$ & $14(13 \cdot 6)$ \\
\hline $10-19$ & $3(12 \cdot 0)$ & $18(23 \cdot 1)$ & $21(20.4)$ \\
\hline $20-29$ & $13(52 \cdot 0)$ & $45(57 \cdot 7)$ & $58(56 \cdot 3)$ \\
\hline$\geqslant 30$ & $3(12 \cdot 0)$ & $7(9 \cdot 0)$ & $10(9 \cdot 7)$ \\
\hline \multicolumn{4}{|l|}{ Cigarette years before the study $\dagger$ : } \\
\hline 0 & $\begin{array}{l}3(12 \cdot 5) \\
5(20 \cdot 8)\end{array}$ & $\begin{array}{rr}1 & (1 \cdot 3) \\
26 & (34 \cdot 2)\end{array}$ & $\begin{array}{rr}4 & (4 \cdot 0) \\
31 & (31 \cdot 0)\end{array}$ \\
\hline $\begin{array}{l}1-99 \\
100-199\end{array}$ & $\begin{array}{l}5(20 \cdot 8) \\
3(12 \cdot 5)\end{array}$ & $\begin{array}{l}20(34 \cdot 2) \\
20(26 \cdot 3)\end{array}$ & $23(23 \cdot 0)$ \\
\hline $200-299$ & $4(16 \cdot 7)$ & $13(17 \cdot 1)$ & $17(17 \cdot 0)$ \\
\hline $300-399$ & $6(25 \cdot 0)$ & $7(9 \cdot 2)$ & $13(13.0)$ \\
\hline $400-799$ & $3(12 \cdot 6)$ & $9(11.9)$ & $12(12 \cdot 0)$ \\
\hline
\end{tabular}

*The average number of cigarettes smoked daily reported in 1988-9.

+Calculated by the average number of cigarettes smoked daily reported in 1980-1 multiplied by the duration of smoking before the study. Values are missing for one male and two females.

\section{SMOKING HABITS DURING FOLLOW UP}

In the study population 99 subjects $(25 \%)$ smoked cigarettes at baseline and throughout the study period, and four subjects $(1 \%)$ started smoking during the study period (table 3 ). Thus the total number of exposed subjects (index category) was $103(26 \%)-25$ men and 78 women. There were 164 subjects $(42 \%)-82$ men and 82 women-who had never smoked (the reference group). The remaining 124 subjects $(32 \%)$ had different types of current and previous exposures to tobacco products. Table 3 gives the distribution of exposure during (in cigarettes per day) and before the study period (in cigarette years) for the index category.

\section{STRATIFIED ANALYSES}

Simple linear regression showed a significant decreasing trend of $\delta \mathrm{FEV}_{1}$ with age in both men and women who had never smoked (the $\dot{\partial}$ reference group, $p<0.01$ ) and smokers (the $\frac{3}{3}$ index group, $\mathrm{p}<0.05)$. In the bivariate 0 analyses of mean $\delta \mathrm{FEV}_{1}$ and potential confounders in men and women only the difference in mean $\delta \mathrm{FEV}_{1}$ between men with occupational exposure to dust ( $-39.2 \mathrm{ml} /$ year) and those $\sigma$ without exposure to dust $(-11.2 \mathrm{ml} /$ year $)$ was significant $(p<0.05)$.

\section{MULTIVARIATE ANALYSES}

There was a significant relation between the average rate of smoking during the study + period and $\delta \mathrm{FEV}_{1}$ (table 4, model 1). The $\frac{0}{0}$ estimate for the adverse effect of smoking on $\stackrel{\mathbb{D}}{\mathbb{P}}$ $\delta \mathrm{FEV}_{1}$ was $-0.42 \mathrm{ml} /$ year for each cigarette $\frac{\rho}{\odot}$ smoked per day during the study period $\triangle$ $(-8.4 \mathrm{ml} /$ year for each pack per day). Taking into account the cumulative exposure before 8 the study period, point estimates for the adverse effects of smoking were $-0.33 \mathrm{ml} /$ year $\overline{0}$. for each cigarette smoked per day during the $\rightleftharpoons$ study period $(-6.6 \mathrm{ml} /$ year for each pack per day) and $-0.97 \mathrm{ml} /$ year per 100 cigarette years of exposure before the study period; neither effect was significant (table 4, model 2). Exposure before and during the study period were 
Table 4 Linear regression models of quantitative effect of cigarette smoking on $\delta F E V$, (ml/year). Main effects models with different exposure variates. Figures are regression coefficients (SE)

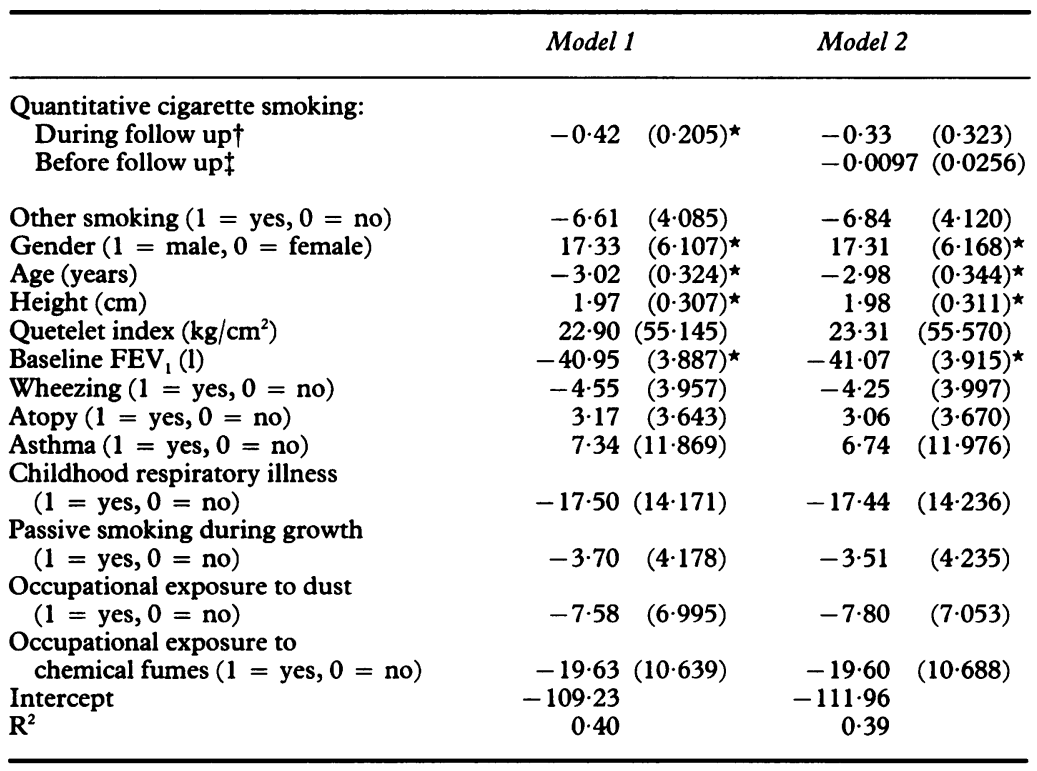

$\star_{\mathrm{p}}<0.05$.

†For each cigarette smoked per day (the average smoking rate during the study period) †For each cigarette year (calculated by the average number of cigarettes smoked daily as reported in 1980-1 multiplied by the duration of smoking before the study in years).

highly corrrelated $(r=0 \cdot 80)$, so collinearity was probably responsible for the lack of significance of the variates when included concurrently in model $2 .^{36}$

Age, gender, height, and baseline $\mathrm{FEV}_{1}$ were all significant determinants of $\delta \mathrm{FEV}_{1}$ in both models with different choices of exposure. None of the other covariates included in the models was significant.

The effect of cigarette smoking on $\delta \mathrm{FEV}_{1}$ was not modified significantly by gender, wheezing, atopy or exposure to environmental tobacco smoke during the growth period.

\section{Discussion}

Our first objective was to provide a quantitative estimate of the effect of cigarette smoking on change in ventilatory lung function over time in young adults. Because of the longitudinal study design it was possible to use individual change in $\mathrm{FEV}_{1}$ as the outcome and the average rate of smoking during the eight year study period as an estimate of exposure. Cigarette smoking before the study period, however, is a potential confounder when studying the effect of cigarette smoking on $\delta \mathrm{FEV}_{1}$ during the study period, and the high correlation between smoking before and during the study period made it difficult to differentiate these two effects. Two models were fitted to illustrate the effects of cigarette smoking. The first model showed a significant dose-response relation between smoking during the study period and $\delta \mathrm{FEV}_{1}$, giving an estimate of annual change of $-8.4 \mathrm{ml}$ for each pack smoked per day, corresponding to an excess decline of $65 \mathrm{ml}$ during the study period. This estimate is likely to include an effect of earlier smoking on $\delta \mathrm{FEV}_{1}$. In the second model, which contained smoking before and during the study period, the effect of smoking during the study period was slightly smaller ( $-6.6 \mathrm{ml} /$ year for each pack smoked per day or $-4.3 \mathrm{ml} /$ year per 100 cigarette years). The effect of smoking before the study period was $-1.0 \mathrm{ml} /$ year per 100 cigarette years. This is compatible with the hypothesis that smoking before the study period has had a slight continued effect on $\delta \mathrm{FEV}_{1}$ during the study period in addition to its effect on initial $\mathrm{FEV}_{1}$. Thus the second model provides for the unconfounded estimate of the effect of smoking during the study period. However, apparently as a result of the high collinearity of smoking before and during the study period neither effect was significant in this model.

Comparison with the estimates from other studies is difficult to make because of differences in age ranges and in definitions of outcome and exposure. The age and $\mathrm{FEV}_{1} /$ height $^{3}$ adjusted estimate of the $\mathrm{FEV}_{1}$ slope of Fletcher et al was $-0.3 \mathrm{ml} /$ year $/ 1000$ packs of lifetime exposure. ${ }^{25}$ Peat et al reported recently a longitudinal study of 225 smokers and 759 never smokers from Australia, in which they estimated the association of the number of cigarettes smoked daily at the end of the study with decline of $\mathrm{FEV}_{1} /$ height $^{3}$ during the preceding years. ${ }^{22}$ The decline of $\mathrm{FEV}_{1}$ after adjusting for age in linear regression was $0.11 \mathrm{ml} / \mathrm{m}^{3} /$ year multiplied by the number of cigarettes smoked daily as reported in the final survey.

When studying the environmental determinants of lung function in young adulthood one of the major issues is how to adjust for the effect of age on the natural evolution of ventilatory lung function. During the age period studied ventilatory function reaches its maximum level and begins a gradual decline with aging. In terms of change in lung function over time we assumed there to be a monotonic decline from a positive to a negative change. A significant linear decreasing relation between $\delta \mathrm{FEV}_{1}$ and age was found in both men and women never smokers and smokers. While a linear relation seems to be a good estimate, it is likely that the true relation is sigmoidal, indicating a plateau between the growth and decline phases. ${ }^{33} 34$

Our second objective was to study modification of the effect of cigarette smoking on $\delta \mathrm{FEV}$, by other factors, with special reference to wheezing. Wheezing, atopy, exposure to environmental tobacco smoke during the growth period, and gender did not modify this relation significantly. Our cross sectional study of the baseline population suggested that wheezing modifies the effect of smoking on $\mathrm{FEV}_{1}$ significantly. ${ }^{24}$ Our finding was consistent with the results of Lebowitz et al in a follow up study of 353 subjects aged $5 \cdot 5$ to 15 years at the time of their initial testing. ${ }^{37}$ They found that those who smoked and had respiratory symptoms (cough, phlegm, wheeze, attacks of shortness of breath or wheeze, or any asthma) had the lowest end point $\mathrm{FEV}_{1}$ and $\mathrm{Vmax}_{50}$ residuals (observed - predicted). We could not, however, find evidence of modification of the effect of smoking on change in FEV by wheezing. Longitudinal study design is usually considered stronger than a cross sectional study 
design, but a lower power due to a smaller number of observations may have been a limitation in studying modification in our study. It is also possible that wheezing develops concurrently with smoking in susceptible smokers. In this case it would be difficult to show the modification during the study period. The question as to whether wheezing indicates susceptibility to the effect of cigarette smoking on change in ventilatory function needs further research.

The proportion of the initial population that is lost to follow up is an important problem in longitudinal studies. In studies similar to ours the follow up rates have varied between $30 \%$ and $75 \%$. ${ }^{10-1214-192338}$ The highest follow up rates have been achieved in studies with a shorter length of follow up-for example, 75\% in the study by Beaty et al with an average follow up time of $4 \cdot 7$ years, ${ }^{17}$ whereas longer follow up times have usually been accompanied by a lower response rate-for example, $30 \%$ of the original population in the study by Kauffmann et al with a follow up of 12 years. ${ }^{11}$ Other studies have not stated clearly the information needed to calculate the exact follow up rate, but the response rates seem to be similar. ${ }^{1320-22}$ A follow up percentage of 38 over eight years was achieved in our study. Although this is relatively low, the study population did not differ significantly from those not followed up with respect to the baseline $\mathrm{FEV}_{1}$ and forced vital capacity or with respect to current cigarette smoking. The difficulty in tracing subjects was not surprising considering that our study population consisted of young adults. Tracing the youngest age groups was especially difficult, as reflected in the comparison of the average baseline age, which was significantly older in the study population than among those lost to follow up for both men and women. The main reasons for subjects moving out of the Montreal area were related to further education or change in job and were not likely to be related to respiratory health status. The lesser occurrence of asthma and wheezing in the study population than in those lost to follow up is at least partly explained by the fact that asthmatic subjects were not contacted in the 1981-2 or 1982-3 surveys. This difference is unlikely to affect the assessment of the effect of smoking because the presence of asthma or wheezing did not have significant independent effects on the outcome, and their potential confounding was controlled in the multivariate analyses.

Our results provide evidence for an adverse effect of cigarette smoking on the evolution of ventilatory lung function already in young adulthood and show that this effect is dose related. As a new methodological approach, smoking before the study period was considered as a potential confounder of the effect of smoking during the study period. Our results suggest that earlier smoking has a slight continued effect on the decline of ventilatory function during the study period in addition to its effect on initial lung function.

We thank Ms Maria Masi for her work in tracing study subjects and data collection, Ms Grace Gerardi for technical assistance in data collection, and Mr Dan Nguyen for record linkage. This study was supported by a grant from the Medical Research
Council of Canada. MSJ was supported by grants from Department of Medicine Research Fund, Royal Victoria Hospital, ment of Medicine Research Fund, Royal Victoria Hospital,
McGill University, and from Ida Montin Foundation, the Finnish Anti-tuberculosis Association, and the Vaino ja Laina Kivi Foundation. PE received the Fraser, Monet, McPherson Faculty Award from McGill University. MRB was career investigator of the Medical Research Council of Canada.

1 Higgins MW, Keller JB, Metzner HL. Smoking, socioeconomic status and chronic respiratory disease. Am Rev Respir Dis 1977;116:403-10.

2 Burrows B, Knudson RJ, Cline MG, Lebowitz MD. Quantitative relationships between cigarette smoking and ventitative relationships between cigarette smoking and ven-

3 Tager I, Tishler PV, Rosner B, Speizer FE, Litt M. Studies of the familial aggregation of chronic bronchitis and obstructive airways disease. Int J Epidemiol 1978;7:55-62.

4 Huhti E, Takala J, Nuutinen J, Poukkula A. Chronic respiratory disease in rural men. An epidemiological survey of Hankasalmi, Finland. Annals of Clinical Research 1978;10:87-94.

5 Manfreda J, Nelson N, Cherniack RM. Prevalence of respiratory abnormalities in a rural and an urban community. Am Rev Respir Dis 1978;117:215-26.

6 Ferris BG Jr, Speizer FE, Spengler JP, et al. Effects of sulfur oxides and respirable particles on human health. Methodology and demography of populations in study. Am Rev Respir Dis 1979;120:767-79.

7 Detels R, Rokaw SN, Coulson AH, Tashkin DP, Sayre JW, Massey FJ Jr. The UCLA population studies of chronic obstructive respiratory disease. I. Methodology and comparison of lung function in areas of high and low pollution. Am J Epidemiol 1979;109:33-58.

8 Beck GJ, Doyle CA, Schachter EN. Smoking and lung function. Am Rev Respir Dis 1981;123:149-55.

9 Dockery DW, Speizer FE, Ferris BG, Ware JG, Louis TA, Spiro III A. Cumulative and reversible effects of lifetime smoking on simple tests of lung function in adults. $A m$ Rev Sespir Dis 1988;137:286-92.

10 Fletcher $C$, Peto $R$. The natural history of chronic airflow obstruction. BMJ 1977;1:1645-8.

11 Kauffmann F, Drouet D, Lellouch J, Brille D. Twelve-year spirometric changes among Paris area workers. Int $J$ Epidemiol 1979;9:201-12.

12 Huhti E, Ikkala J. A 10-year follow-up study of respiratory symptoms and ventilatory function in a middle-aged rura population. Eur J Respir Dis 1980;61:33-45.

13 Woolf CR, Zamel N. The respiratory effects of regular cigarette smoking in women. A five-year prospective study. Chest 1980;78:707-13.

14 Van der Lende $R$, Kot TJ Peset Reig $R$, Quanier $\mathbf{P h H}$ Schouten JP, Orie NGM. Decreases in VC and FEV, with Schouten JP, Orie NGM. Decreases in VC and FEV, with time: indicators for effects of smoking and air

15 Bosse R, Sparrow D, Rose CL, Weiss ST. Longitudinal effect of age and smoking cessation on pulmonary function. Am Rev Respir Dis 1981;123:378-81.

16 Beck GJ, Doyle CA, Schachter EN. A longitudinal study of respiratory health in a rural community. Am Rev Respir Dis 1982;125:375-81.

17 Beaty TH, Menkes HA, Cohen PH, Newill CA. Risk factors associated with longitudinal change in pulmonary function. Am Rev Respir Dis 1984;129:660-7.

18 Krzyzanowski $M$, Jedrychowski $W$, Wysocki $M$. Factors associated with the change in ventilatory function and the associated with the change in ventilatory function and the development of chronic obstructive pulmonary disease in a 13-year follow-up of the Cracow study. Risk of chronic
obstructive pulmonary disease. Am Rev Respir Dis 1986; obstructive p

19 Camilli AE, Burrows B, Knudson RJ, Lyle SK, Lebowitz $M D$. Longitudinal changes in forced expiratory volume in one second in adults. Effects of smoking and smoking cessation. Am Rev Respir Dis 1987;135:794-9.

20 Lange P, Groth S, Nyboe J, et al. Effects of smoking and changes in smoking habits on the decline of FEV Respir $J$ 1989;2:811-6.

21 Lange $\mathrm{P}$, Groth S, Nyboe J, et al. Decline of the lung function related to the type of tobacco smoked and inhalation. Thorax 1990;45:22-6.

22 Peat JK, Woolcock AJ, Cullen $K$. Decline of lung function and development of chronic airflow limitation: a longiand development of chronic airflow limitation: a longitudinal study of non-smokers and smokers

23 Tager IB, Munoz A, Rosner B, Weiss ST, Carey V, Speizer FE. Effect of cigarette smoking on the pulmonary function of children and adolescents. Am Rev Respir Dis 1985 131:752-9.

24 Jaakkola MS, Jaakkola JJK, Ernst P, Becklake MR. Ventilatory lung function in young cigarette smokers: a study of susceptibility. 24. Eur Respir J 1991;4:643-50.

25 Fletcher C, Peto R, Tinker C, Speizer FE. The natural history of chronic bronchitis and emphysema. An 8-year study of working men in London. London: Oxford University Press, 1976.

26 Higgins M. Epidemiology of COPD: state of art. Chest 1984;85(suppl 6):3-8S

27 Surgeon General. The health consequences of smoking; chronic obstructive lung disease. Rockville, Maryland: United States Department of Health and Human Services, Office on Smoking and Health, 1984. 
28 Leech JA, Chezzo H, Stevens D, Becklake MR. Respiratory pressures and function in young adults. Am Rev Respir Dis 1983;128:17-23.

29 Ferris BG Jr. Epidemiology standardization project. $A m$ Rev Respir Dis 1978;118:1-120.

30 American Thoracic Society. Medical section of the American Lung Association. Standardization of spirometry-1987 update. Am Rev Respir Dis 1987;136: 1285-98.

31 Vollmer WM, Johnson LR, McCamant LE, Buist AS. Methodologic issues in the analysis of lung function data. Journal of Chronic Diseases 1987;40:1013-23.

32 Knudson RJ, Lebowitz MD, Holberg CJ, Burrows B Changes in the normal maximal expiratory flow-volume curve with growth and aging. Am Rev Respir Dis 1983; 127:725-34.

33 Burrows B, Cline MG, Knudson RJ, Taussig LM, Lebowitz $M D$. A descriptive analysis of the growth and decline of the FVC and $\mathrm{FEV}_{1}$. Chest 1983;83:717-24

34 Tager IB, Segal MR, Speizer FE, Weiss ST. The natural history of forced expiratory volumes. Effect of cigarette smoking and respiratory symptoms. Am Rev Respir Dis 1988;138:837-49.

35 Miettinen OS. Theoretical epidemiology. Principles of occurrence research in medicine. New York: John Wiley, 1985: 216-44.

36 Kleinbaum DG, Kupper LL, Muller KE. Applied regression analysis and other multivariable methods. Boston: PWS-KENT Publishing Company, 1988:206-21.

37 Lebowitz MD, Holberg CJ, Knudson RJ, Burrows B

Longitudinal study of pulmonary function development in childhood, adolescence, and early adulthood. Development of pulmonary function. Am Rev Respir Dis 1987; 136:69-75.

38 Higgins MW, Keller JB, Becker M, et al. An index of risk for obstructive airways disease. Am Rev Respir Dis 1982; 125:144-51. 